\title{
TOWARDS A METHODOLOGY FOR QUANTIFYING THE BENEFITS OF BIM
}

\author{
Ilias Krystallis ${ }^{1}$, Eleni Papadonikolaki ${ }^{1}$, Ornella Iuorio ${ }^{2}$ and Giorgio Locatelli ${ }^{2}$ \\ ${ }^{1}$ The Bartlett School of Construction and Project Management, London, UK \\ ${ }^{2}$ School of Civil Engineering, Leeds, UK
}

\begin{abstract}
The adoption of Building Information Modelling (BIM) which offers integrated software and processes for digital delivery, is becoming imperative for the UK construction industry. Literature thus far is unclear if the benefits claimed by the industry are exaggerated for commercial reasons. Our exploratory study investigates how the benefits of adopting BIM can be quantified. The findings reported through a focus group of industry experts specialising in digital innovation offers a reality check at project/firm/sector level to scrutinize the benefits and costs of BIM. The key results offer four areas the construction sector could further investigate to report monetary benefits and costs of BIM. The study thus provides insight into how businesses can develop a robust but adaptable methodology for capturing BIM costs and benefits.
\end{abstract}

\section{Introduction}

The British Standards Institution (BSI, 2014) defines a Smart City as one where "there is effective integration of physical, digital and human systems in the built environment to deliver a sustainable, prosperous and inclusive future for its citizens". Novel digital technologies and particularly Building Information Modelling (BIM) as a form of systemic innovation (Succar and Kassem, 2015) promise to revolutionise the way buildings and infrastructure are designed and operated. The vision for upgrading infrastructure and developing (digital) skills is of significant national importance in the UK (BEIS, 2017). At the same time, the UK Industrial Strategy (BEIS, 2017) prioritises innovation and increasing productivity as key areas for strengthening the economic performance of cities across regions, beyond the South East and London that pull performance around the country. To this end, British industry and policy players recommended BIM as a solution to improve productivity and efficiency (Azhar, 2011). By enabling improved collaboration and coordination, BIM has the potential to deliver project benefits such as better control, as well as enhanced project and asset performance (Love et al., 2013; Love et al., 2014; Papadonikolaki et al., 2017; Papadonikolaki and Wamelink, 2017). Recent developments such as the vision of the Digital Built Britain strategy (BEIS, 2015) which focuses on charting digitalisation, including and beyond BIM, and the Smart Cities agenda indicate that unbiased and scientific assessment of the benefits and costs of BIM adoption is needed.
An early effort to capture and operationalise the benefits and return on investment from using digital technologies started in the UK in 2002 known as the Avanti project (CPIC, 2013). The Avanti project showed that while digital technologies - back then called computer-aided - necessitate substantial learning, integrating these technologies with the complex, interdependent work in the construction industry is challenging (Morgan, 2017). According to the Department of Trade and Industry, Avanti reported a number of promising benefits.

Nevertheless, although the Avanti project demonstrated the potential use of Information Technology (IT) and became the basis of the BIM British Standards (BS) 1192, it relied on technology which is now redundant. The proposed study aims to operationalise the benefits and costs of the digital based on updated information from current technologies and practices.

This study provides an appraisal of BIM costs and benefits during the design, construction and operation phases of infrastructure. It aims to provide demonstrable appraisal of BIM costs and benefits to support the industry into adopting a digital way of working. It builds on the success of previous initiatives, which focused only on the design phases, by extending the scope to construction as well and investigating the impact of recent technological advancements in digitalisation across the construction supply chain.

\section{Quantification of BIM costs and benefits}

Various scholars have studied the benefits of BIM in development and operation asset life (Love et al., 2014, Krystallis et al 2015). However, BIM benefits are neither fully operationalized nor measured in a quantitative manner. The result is a lack of tangible and demonstrative outcomes able to further disincentive construction firms or their customers, who are still reluctant in adopting BIM and transforming digitally their businesses. For instance, in a study commissioned by the UK government, the BIM experts shared that "application of BIM is expected to have a $10 \%$ capex reduction for Small Modular Reactors which is consistent with savings achieved for other industries. And, the capex reduction can even go up to $20 \%$ in some cases" (BEIS, 2015). Accordingly, they expect proportionally similar benefits for new large reactors. 
Looking at the scientific and practitioners' literature is clear that the claims about BIM benefits are mostly anecdotal, provided by stakeholders with a vested interest, and might be subject of "cherry picking", i.e. reporting only favorable outcomes. A recent report prepared by $\mathrm{PwC}$ on a methodology to evaluate the performance of BIM Level 2 provided results of savings of $3 \%$ in total, with savings deriving mainly from the operational stage $(5.5 \%)$ and only validated through two cases (PwC, 2018). Also, a recent international study supported by the Danish government showed cost reductions up to $7 \%$ by using an online digital communications platform and BIM on large-scale construction projects (Lambrecht, 2017). This ambiguity justifies further research in cost and benefits of BIM. Indeed, in the UK and abroad, policies and major investments are decided using data and information about BIM benefits that might be unreliable. Based on this, the UK BIM and the Digital Built Britain strategies should avoid the pitfall of previous "deterministic change agendas" (Dainty et al., 2017).

\section{Methods}

The study builds on data collected through a focus group. In July 31st, 2018 the authors organised a stakeholders engagement workshop. All participants had professional experience in the UK construction sector. The focus group workshop aimed to explore the actual monetary cost savings/cost implications of adopting BIM. Ten senior experts from the UK industry, government, academic and research organisations participated. The participants were carefully selected because of their leading capacity in driving digitalization in their organizations. A total of four activities were organised into discussion topics (presented in detail below). For the first three activities, the participants were split into three groups. This allowed the team to investigate each topic in depth by carrying three rounds of data collection, whilst also minimising potential authority bias (Milgram, 1963).

The focus group workshop was divided into four key topics of discussion as summarised in Figure 1.

In term of data analysis, emergent theme analysis was applied to analyze and interpret the data (Creswell, 2017). Each of the co-authors acted as a facilitator for one of the four topics and was responsible for reporting the findings.

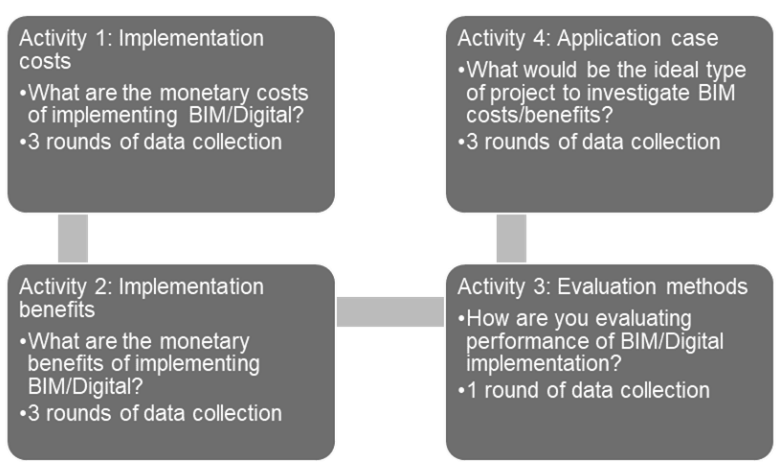

Figure 1. Workshop activities sequence

\section{Results}

In the remainder of this paper, we report the findings from the focus group. The findings are organized in four areas.

\section{BIM costs}

The quantification of key monetary BIM costs requires analyzing both upfront and maintenance costs, looking at the full building/infrastructure life cycle. In terms of upfront costs, the main streams are a) software and technology acquisition; and b) staff training according to the focus group. The implementation of BIM requires a complete shift from the linear system to parametric modelling, that is mostly based on new software, which requires both upfront costs such as license purchasing and staff training, as well as maintenance costs for license updating. The new routines involve the analysis of a larger number of data, which also requires powerful Internet connections and hardware, up to the adoption of cloudcomputing.

The focus group indicated that the introduction of BIM has strongly differentiated the typology of their work within design and construction companies. Indeed, together with more traditional figures of architects, engineers, the new system requires people capable to perform program tasks, as well as capable of working on different platforms that can operate in parallel or in sequence. Therefore, higher investments are needed for training of current employees, investment in new highly skilled IT individuals and the involvement of technical support teams that can constantly allow the development of new skills, in a fast-evolving environment. Indeed, knowledge is fast evolving, and constant updates of protocols are required.

A good example was provided by the engineering company representatives, which envisages all information generated across contributing engineering disciplines to be made available between all design platforms through common means known as Common Data Environment (CDE) (Gerrish T., 2017). To reach this goal, the supply chain is aiming to develop their team's capabilities across four knowledge levels, as detailed in Table 1. 
The industry is dealing with taking everyone to move from Level 1 to 2 as shown in Table 1 , and is introducing individuals with coding skills, so that in the long-term, a large percentage of models will live in the CDE.

The application of BIM in the design phase is associated with the development of projects from the initial design, across architecture, structure and mechanical systems, to onsite work. However, one of the claimed BIM strengths sits in its implementation for the management of the building/infrastructure during the operation and end of life phases. Considering that, in the design and construction phase, the maintenance procedure can be defined and stored in the BIM platform, the maintenance procedure is defined according to lifetime scenarios. However, the scenarios often change in real life.

Table 1: Knowledge levels

\begin{tabular}{|l|l|}
\hline $\begin{array}{l}\text { Knowledge } \\
\text { levels }\end{array}$ & Details \\
\hline $\begin{array}{l}\text { Level 1: } \\
\text { Opening a } \\
\text { protocol }\end{array}$ & $\begin{array}{l}\text { The ability to open a BIM file } \\
\text { and read and understand its } \\
\text { context. Basic information can } \\
\text { be obtained only. }\end{array}$ \\
\hline $\begin{array}{l}\text { Level 2: } \\
\text { Creating a } \\
\text { protocol }\end{array}$ & $\begin{array}{l}\text { The ability to create a BIM file } \\
\text { from established company BIM } \\
\text { templates. The user can create a } \\
\text { parametric BIM 3D model and } \\
\text { use the company's BIM library } \\
\text { of components. }\end{array}$ \\
\hline $\begin{array}{l}\text { Level 3: } \\
\text { Writing code }\end{array}$ & $\begin{array}{l}\text { The ability to use graphical } \\
\text { programming tools that allows } \\
\text { the user to customize the } \\
\text { building information workflow. }\end{array}$ \\
\hline $\begin{array}{l}\text { Level 4: } \\
\text { Creating } \\
\text { models for the } \\
\text { Common Data } \\
\text { Environment } \\
\text { (CDE) }\end{array}$ & $\begin{array}{l}\text { The ability to create company } \\
\text { and project-wide templates so } \\
\text { users can work in common } \\
\text { standards. The 3D model's } \\
\text { metadata are formatted so users } \\
\text { can carry interrogations in the } \\
\text { CDE. }\end{array}$ \\
\hline
\end{tabular}

Therefore, updates of the maintenance procedure are required, with the necessity of including, in some cases, special works (such as retrofit) to be undertaken under exceptional circumstances. These situations can be caused either due to hazards (i.e. flooding, hurricanes), strong degradations, or change of usage. All these unpredictable events will strongly alter the physical asset's function and use and, therefore, the digital twin associated with it, should be updated. The complex lifecycle scenarios of the asset still pose many challenges and uncertainties in the real functioning of maintenance and accuracy of its digital twin. Therefore, actual asset's lifecycle costs are difficult to be quantified and to a large degree, are arbitrary.

\section{BIM benefits}

In the development and execution phases, the main improvements from BIM lie in it being a major enabler for stakeholders to collaborate. Stakeholders can access the latest designs and models, improving the synchronization and therefore coordination in the information sharing and the visualization of the future building/infrastructure. This leads to benefits including:

- $\quad$ Reduction of mistakes and therefore rework and waste. Better information sharing, visualization and synchronization prevent many of the underpinning causes leading to mistakes (e.g. working with old design).

- Better collaboration, creating less misunderstanding, leading to a better relationship between the stakeholders reducing the opportunities for conflict and litigation

- $\quad$ Better time management: often designers use all the available time to produce a design up to when they provide construction documents to the contractor or the customers. Changes in the final phase, straight before the documentation delivery, can imply delays and a waste of the hours spent in making the original design. With the adoption of BIM, contractors and customers can visualize the proposed project earlier in the design process, with the consequent possibility to provide early feedback about both constructability (the contractor) and operation (the user).

- $\quad$ The quality intended as the satisfaction of the operator/end user implicit and explicit need of the "end product" (i.e. the building/infrastructure) is higher.

- BIM is an enabler for the offsite construction/factory fabrication and modularization. Offsite construction and modularization can generate time and cost savings because the operations are more efficient, the quality is higher and the number of mistakes lower (Mignacca et al., 2018).

In operations, a BIM model can keep track of the story of the building/infrastructure collecting valuable data for the decision making. This dataset can include information for example, about equipment failing, and maintenance routines, with consequences in:

- Reduction of maintenance costs. A key advantage of adopting BIM is the possibility to give the right information to the right person at an appropriate time.

- $\quad$ Reduction of retrofitting costs. Keeping track of the history of each BIM element, system and ideally module can provide valuable information about when and how retrofitting is needed. BIM can be used as a 
simulation tool to test different possible retrofitting solutions.

- $\quad$ Energy and other operations cost reductions: Use of smart systems that know when a certain service is needed. For instance, a room used only for limited hours a day can be programmed to be warmed during these hours, thus resulting in energy costs savings.

\section{BIM process evaluation methods}

The focus group findings on how to measure the benefits/costs of BIM adoption fell largely into two distinct categories: internal metrics - whereby organizations develop their own approach to evaluate benefits and costs; and external organization metrics whereby organization employ methodologies found in the market and embed in their routines. The internal metrics and measurements methodologies, first included firm-wide developed assessment tools for measuring BIM outcomes. Azzouz et al. (2016) shows as at least seventeen assessment tools developed globally, both in academia and practice. The pluralism of these various BIM assessment methods relates to different firm strategies and in-house performance tracking routines as well as the myriad of interpretations regarding BIM. Another source of internal metrics to evaluate the performance of BIM adoption was suggested as being data from Human Resources such as payment data and "time spent on projects". However, the participants agreed that performance evaluation processes hardly ever take place in firms because they are not ingrained in company culture. Finally, workshop participants suggested as a source of data for measuring BIM benefits/costs the utilization of data on documents' revision and change management as well as data from clash reports to compare projects with and without BIM implementation.

Regarding the use of external tools and methodologies, the participants suggested the use of the methodology developed by PwC (2018), although there is no proof that the methodology has been used to date. The methodology can be applied to estimate economic benefits that may be realized across the asset lifecycle. A limitation is however that the methodology does not consider the costs of implementing BIM. Similarly, some participants mentioned regular use of the tool developed by Scottish Futures Trust (2018) on assessing Return of Investment (ROI) from BIM implementation. Additionally, the participants displayed an awareness of the Avanti Project but acknowledged that the benefits reported there were about how to map technology in a process, however BIM changes the process of working. Finally, the participants suggested the organizational portfolio of new and repeated businesses as a way for defining the cost and benefits of BIM adoption.

\section{Applicability}

This section describes the key characteristics a construction project should have that would help realize the investigation about the monetary benefits and costs of BIM. According to the experts, the opportunity to investigate the monetary costs and benefits of BIM exists in projects that carry the following characteristics:

Complexity: The greater the complexity of the project, the greater the need for the project to be developed and executed in a BIM environment. The more complex the project, the greater the benefits but also potentially greater the costs of implementing this kind of technology.

Multi-disciplinary projects: Future investigations should look at projects that are multi-disciplinary in nature. Because of the involvement of multiple stakeholders, it is anticipated that greater benefits will be achieved with BIM.

Type of project: Future investigations should consider construction projects in general not just buildings. According to the experts, infrastructure projects provide better data compared to building projects.

Next, the experts discussed approaches regarding the development of the methodological approach of capturing the monetary costs and benefits. The following features were discussed:

Project phase: According to the experts capturing monetary BIM benefits is difficult during the operation phase. Because it is difficult to gather data, estimation of BIM costs and benefits becomes more challenging compared to the design and construction phases. As a result, the value of the findings decreases, and the research methodology would provide questionable results.

Set of projects: The collection of data should include multiple cases, not rely on the validity of outputs resulting from just a few projects. This should help tackle the uniqueness issue often identified in the sector. As such, the research methodology would offer a balanced approach and findings can be generalized to all construction projects with the characteristics mentioned above.

Requirements capture: The methodology should be flexible to capture and document various benefits and costs. The tool should have flexibility built in to accommodate various sets of benefits as one project's vision could be different from another. Thus, this needs to be reflected in the way benefits are reported.

Procurement route variation: The methodology should have the capacity to measure BIM costs and benefits from projects of various procurement routes. For example, design and build projects are very different compared to Private Finance Initiative (PFI) 
projects in various fronts. Thus, the costs and benefits are expected to be different in these two project types. The tool however could benchmark whether BIM benefits in a PFI project outperform the benefits found in a project delivered by a Design and Build contract.

Non-BIM Vs BIM comparative cases to measure BIM benefits/costs: The methodology could leverage a cross-case study between BIM and non-BIM projects that are identical in most aspects and use this as a baseline.

Client engagement: Further engagement was suggested, especially capturing the views of the respective project client to further shape and balance the inputs/outputs of the methodology.

Deployment approach: The methodology/tool should include handbooks, toolkits and on-site mentoring about how benefits are collected, measured and tested.

Table 2 illustrates a summary of key findings from the workshop.

\section{Conclusions}

Concerns that construction projects are not delivering full value to the public has called for Government action to mandate BIM in the construction sector as a digital-driven change initiative that promises better gains for public sector investments. Evidence suggests that the process upon how the monetary costs and benefits of BIM are captured remains a black box in the industry. The review suggests that it is still not clear in the construction sector what are the monetary costs and benefits of BIM. A reality check is needed at project/firm/sector level to shed light whether the benefits of BIM are reaped.

The importance and urgency of developing a robust but flexible methodology for measuring these costs and benefits is presented in this paper. In this context, the types of benefits, costs, evaluation methods and projects to be tested was presented. Such a methodology would prove useful to both client organizations and supply chain organizations who wish to invest in BIM or indeed have incorporated BIM in their business and questioning the validity of its use. In terms of limitations and future research, the study's findings are grounded in the context of UK construction sector, and stakeholders reflections looked particularly how BIM is adopted and measured in the UK context. As such, the findings presented in this paper are applicable only in a UK construction sector. Future research should text if propositions in this paper are true. A comparative multi-national case study would be appropriate as way forward.

\section{References}

Azhar, S. (2011) Building Information Modeling (BIM): Trends, benefits, risks and challenges for the AEC industry. Leadership and Management in Engineering, 11, 241-252.

Azzouz, A., Shepherd, P. and Copping, A. (2016) June. The Emergence of Building Information Modelling Assessment Methods (BIM-AMs). In Integrated Design International Conference, Bath, UK

BEIS, (2015) Digital Built Britain, Level 3 BIM Strategic Plan [online]. HM Government. Available

Table 2: Summary of key findings from the focus group

\begin{tabular}{|c|c|c|c|}
\hline BIM costs & BIM benefits & $\begin{array}{l}\text { BIM evaluation } \\
\text { methods }\end{array}$ & Applicability \\
\hline $\begin{array}{l}\text { Upfront costs due to: } \\
\text { - Software acquisition } \\
\text { and updates } \\
\text { - Hardware (e.g. cloud } \\
\text { computing) for } \\
\text { increasing data } \\
\text { capacity } \\
\text { - Existing Staff training } \\
\text { - Hire of skilled IT } \\
\text { staff } \\
\text { - Development of } \\
\text { processes, templates, } \\
\text { workflows including } \\
\text { maintenance } \\
\text { - Client education }\end{array}$ & $\begin{array}{l}\text { Cost reductions in } \\
\text { construction due to: } \\
\text { - less rework due to } \\
\text { design or construction } \\
\text { errors } \\
\text { - limited scope change } \\
\text { Cost reductions in } \\
\text { operation due to: } \\
\text { - improved } \\
\text { maintenance } \\
\text { - enhanced optimal } \\
\text { usage of the asset }\end{array}$ & $\begin{array}{l}\text { Internal tools and data: } \\
\text { - } \quad \text { In-house developed } \\
\text { evaluation matrices } \\
\text { - } \quad \text { Human Resources } \\
\text { payment data } \\
\text { - Revisions and change } \\
\text { management data } \\
\text { - Clash reports data } \\
\text { External tools: } \\
\text { - Scottish Future Trust } \\
\text { - Avanti methodology } \\
\text { - BRE project KPIs } \\
\text { Other indicators: } \\
\text { - Repeat businesses } \\
\text { - Profit }\end{array}$ & $\begin{array}{l}\text { The methodology needs } \\
\text { to reflect: } \\
\text { - Project complexity } \\
\text { level } \\
\text { - Project } \\
\text { - Multidisciplinarity } \\
\text { - Project type variation } \\
\text { - Project Phases } \\
\text { - Requirements capture } \\
\text { - } \text { flexibility } \\
\text { - Brocurement route } \\
\text { - } \text { project cases } \\
\text { - Client input } \\
\text { - Deployment package }\end{array}$ \\
\hline
\end{tabular}


from:

https://www.cdbb.cam.ac.uk/news/2015DBBStrategy

BEIS, (2017) Industrial Strategy: Building a Britain fit for the future [online]https://www.gov.uk/government/uploads/syst em/uploads/attachment_data/file/664563/industrialstrategy-white-paper-web-ready-version.pdf

BSI, (2014) Smart cities framework - Guide to establishing strategies for smart cities and communities, PAS 181:2014.

CPIC, (2013) Report from The Construction Research Programme - Project Showcase. [online] Available from: https://www.cpic.org.uk/publications/avanti/

Creswell, J.W. and Creswell, J.D. (2017) Research design: Qualitative, quantitative, and mixed methods approaches. Sage publications.

Dainty, A., Leiringer, R., Fernie, S. \& Harty, C. (2017) BIM and the small construction firm: a critical perspective. Building Research \& Information, 1-14.

Gerrish, T. (2017) Exploring the effectiveness of BIM for energy performance management of non-domestic buildings, Doctor of Engineering (EngD) thesis, Loughborough University.

Lambrecht, J.F. (2017) Measuring the effects of using the IT concept: A research project conducted in cooperation with GenieBelt. Copenhagen, Denmark: Statensbyggeforskningsinstitut \& Aalborguniversitet.

Krystallis, I., Demian, P. and Price, A.D. (2015) Using BIM to integrate and achieve holistic future-proofing objectives in healthcare projects. Construction Management and Economics, 33(11-12), pp.890-906.

Love, P.E., Simpson, I., Hill, A. and Standing, C. (2013) From justification to evaluation: Building information modeling for asset owners. Automation in construction, 35, pp.208-216.

Love, P.E., Matthews, J., Simpson, I., Hill, A. \& Olatunji, O.A. (2014) A benefits realization management building information modeling framework for asset owners. Automation in Construction, 37, 1-10.

Mignacca, B., Locatelli, G., Alaassar, M. and Invernizzi, D.C. (2018) We Never Built Small Modular Reactors (SMRs), but What Do We Know About Modularization in Construction?. In 2018 26th International Conference on Nuclear Engineering (pp. V001T13A012-V001T13A012). American Society of Mechanical Engineers.

Milgram, S. (1963) Behavioral study of obedience. The Journal of abnormal and social psychology, 67(4), p.371.

Papadonikolaki, E., Verbraeck, A. and Wamelink, H. (2017) Formal and informal relations within BIM- enabled supply chain partnerships. Construction Management and Economics, 1-22.

Papadonikolaki, E. and Wamelink, H. (2017) Interand intra-organizational conditions for supply chain integration with BIM. Building Research \& Information, 1-16.

PwC, (2018) BIM Level 2 Benefits Measurement: Application of PwC's BIM Level 2 Benefits Measurement Methodology to Public Sector Capital Assets. [online] https://www.cdbb.cam.ac.uk/BIMLevels/BBM.

Scottish Futures Trust, (2018) BIM Return on Investment Tool. [online] https://bimportal.scottishfuturestrust.org.uk/page/roicalculator

Succar, B. and Kassem, M. (2015) Macro-BIM adoption: Conceptual structures. Automation in Construction, 57, pp.64-79. 